\title{
A first insight into the genome of Prototheca wickerhamii, a major causative agent of human protothecosis
}

\author{
Zofia Bakuła ${ }^{1}$, Paweł Siedlecki ${ }^{2,3}$, Robert Gromadka ${ }^{4}$, Jan Gawor ${ }^{4}$, Agnieszka Gromadka ${ }^{3}$, Jan J. Pomorski ${ }^{5}$, \\ Hanna Panagiotopoulou ${ }^{5}$ and Tomasz Jagielski ${ }^{*}$
}

\begin{abstract}
Background: Colourless microalgae of the Prototheca genus are the only known plants that have consistently been implicated in a range of clinically relevant opportunistic infections in both animals and humans. The Prototheca algae are emerging pathogens, whose incidence has increased importantly over the past two decades. Prototheca wickerhamii is a major human pathogen, responsible for at least 115 cases worldwide. Although the algae are receiving more attention nowadays, there is still a substantial knowledge gap regarding their biology, and pathogenicity in particular. Here we report, for the first time, the complete nuclear genome, organelle genomes, and transcriptome of the P. wickerhamii type strain ATCC 16529.

Results: The assembled genome size was of $16.7 \mathrm{Mbp}$, making it the smallest and most compact genome sequenced so far among the protothecans. Key features of the genome included a high overall GC content (64.5\%), a high number (6081) and proportion (45.9\%) of protein-coding genes, and a low repetitive sequence content (2.2\%). The vast majority (90.6\%) of the predicted genes were confirmed with the corresponding transcripts upon RNA-sequencing analysis. Most (93.2\%) of the genes had their putative function assigned when searched against the InterProScan database. A fourth (23.3\%) of the genes were annotated with an enzymatic activity possibly associated with the adaptation to the human host environment. The $P$. wickerhamii genome encoded a wide array of possible virulence factors, including those already identified in two model opportunistic fungal pathogens, i.e. Candida albicans and Trichophyton rubrum, and thought to be involved in invasion of the host or elicitation of the adaptive stress response. Approximately $6 \%$ of the P. wickerhamii genes matched a Pathogen-Host Interaction Database entry and had a previously experimentally proven role in the disease development. Furthermore, genes coding for proteins (e.g. ATPase, malate dehydrogenase) hitherto considered as potential virulence factors of Prototheca spp. were demonstrated in the P. wickerhamii genome.
\end{abstract}

Conclusions: Overall, this study is the first to describe the genetic make-up of $P$. wickerhamii and discovers proteins possibly involved in the development of protothecosis.

Keywords: Alga, Prototheca wickerhamii, Protothecosis, Virulence, Whole genome sequencing

\footnotetext{
* Correspondence: t.jagielski@biol.uw.edu.pl

'Department of Medical Microbiology, Institute of Microbiology, Faculty of Biology, University of Warsaw, I. Miecznikowa 1, 02-096 Warsaw, Poland

Full list of author information is available at the end of the article
}

C C The Author(s). 2021 Open Access This article is licensed under a Creative Commons Attribution 4.0 International License, which permits use, sharing, adaptation, distribution and reproduction in any medium or format, as long as you give appropriate credit to the original author(s) and the source, provide a link to the Creative Commons licence, and indicate if changes were made. The images or other third party material in this article are included in the article's Creative Commons licence, unless indicated otherwise in a credit line to the material. If material is not included in the article's Creative Commons licence and your intended use is not permitted by statutory regulation or exceeds the permitted use, you will need to obtain permission directly from the copyright holder. To view a copy of this licence, visit http://creativecommons.org/licenses/by/4.0/. The Creative Commons Public Domain Dedication waiver (http://creativecommons.org/publicdomain/zero/1.0/) applies to the data made available in this article, unless otherwise stated in a credit line to the data. 


\section{Background}

The chlorophytan genus Prototheca contains aerobic, unicellular, colourless, yeast-like algae, able to cause disease in humans and other mammals, referred to as protothecosis. In fact, among all the Viridiplantae, only Prototheca and Chlorella microalgae possess a pathogenic potential for both humans and animals [1-4]. Prototheca spp. normally live as saprophytes and are environmentally ubiquitous, having been isolated from water, soil, slime flux of trees, raw and treated sewage, animal faeces, and food products $[1,5]$.

Since the first description of the Prototheca genus by Krüger in 1894 [6], its taxonomic position has been disputed for over a century, due to some apparent phenotypic similarities with yeasts. Currently, the Prototheca spp. are accepted to belong to the family Chlorellaceae of the order Chlorellales, in the class Trebouxiophyceae. Phylogenetically, their closest photosynthetic relative is Auxenochlorella protothecoides [7]. The Prototheca algae also share a close relationship with non-photosynthetic algae of the genus Helicosporidium, which are obligate parasites of arthropods, especially insects. Interestingly, the Helicosporidia seem to be basal to the A.protothecoides and Prototheca clades, implying that the loss of photosynthesis must have occurred at least twice in the evolution of heterotrophic Chlorellales [7].

The issue of molecular taxonomy of Prototheca spp. has been exhaustively addressed in a very recent work by Jagielski et al. [4]. Based on the partial cytb gene sequences, the genus was shown to accommodate 14 species. They all fell into two main lineages, i.e. cattleassociated (i.e. Prototheca ciferrii, formerly Prototheca zopfii gen. 1, Prototheca blaschkeae, and Prototheca bovis, formerly Prototheca zopfii gen. 2) and humanassociated (i.e. Prototheca wickerhamii, Prototheca cutis, Prototheca miyajii) [4]. More recently, a new species of Prototheca paracutis has been described [8].

Prototheca wickerhamii is a major etiological agent of human protothecosis. The disease was first reported in 1964 in Sierra Leone [9], and since then, at least 211 new cases have been described in the literature [10]. Clinically, protothecosis manifests in three predominant forms, namely: cutaneous, olecranon bursitis, and disseminated or systemic disease. Protothecal infections are believed to develop through contact with potential sources (e.g. contaminated water), often following minor injuries or surgical interventions. Still, the exact portals of entry and mechanisms of pathogenesis in protothecosis remain obscure.

There is no standardized treatment protocol for protothecosis. Antifungal agents including the azoles (ketoconazole, itraconazole, fluconazole) and amphotericin B have been most commonly used, with the latter producing the best activity against Prototheca spp. [10].
The Prototheca algae and protothecosis have been much neglected areas of research. Studies on the genetic level are seriously lacking. Importantly, sequencing of the entire chromosomal DNA has so far been attempted in four species, i.e. P. ciferrii, P. bovis, P. cutis, and Prototheca stagnora, with the results released only in a draft format [11-13]. Although five reports have been published on mitochondrial and plastid genomes of $P$. wickerhamii, they all used the SAG 263-11 strain [7, 14-17], which in the light of the new Prototheca taxonomy represents not $P$. wickerhamii, but a completely different species, designated as Prototheca xanthoriae [4]. Only this year, has the first description of the organellar genomes of a true $P$. wickerhamii been published [18].

The objective of this study was to perform, for the first time, the genome-wide sequencing with thorough structural and functional analysis of the $P$. wickerhamii type strain, using a combination of PacBio and Illumina sequencing technologies. A subsequent transcriptomeproteome profiling was carried out to support the assembly completeness. This work also provides a first insight into protothecal pathogenesis, with several approaches used to select genes putatively involved in the virulence of $P$. wickerhamii.

For the comparative purposes, genomes of other Prototheca spp. and their closest relatives (A. protothecoides and Helicosporidium sp.) were included in the analysis. Furthermore, iconic fungal pathogens, including a yeast Candida albicans and a dermatophyte Trichophyton rubrum were used to search possible virulence factors. This was done due to some apparent phenotypic similarities (morphological and biochemical) shared between $P$. wickerhamii and fungi, particularly yeasts.

\section{Results and discussion}

\section{General features of the $P$. wickerhamii nuclear genome} Nuclear genome assembly and quality assessment

Sequencing of the $P$. wickerhamii chromosome produced a total of 2,429,822,821 and 2,198,163,916 nucleotides and $8,239,274$ and 286,004 reads for Illumina and PacBio, respectively. Those reads were further assembled into 21 contigs and as many scaffolds with an N50 length of $1,578,614 \mathrm{bp}$. The assembled sequencing data hence represented an average sequence depth of $150 x$, with the longest scaffold size of 2,447,261 bp. The high quality of the genome assembly was confirmed with the BUSCO analysis (Supplementary Figure S1). Furthermore, the RNA-mapping rate dataset supported the high assembly completeness. Among 10,963,602 read pairs from RNA-sequencing experiment, $90.64 \%$ uniquely mapped to the genome, while 0.94 and $0.01 \%$ mapped to multiple $(>1)$ or too many (>10) loci, respectively. The vast majority $(89.86 \%)$ of the mapped reads fell within predicted coding regions, suggesting that the total 
coding potential of the Prototheca organism was wellrepresented in the genome. Among predicted and annotated genes only $9.4 \%$ (573) did not have any overlaps with RNA-sequencing data.

\section{Nuclear genome characteristics and gene prediction}

The general features of the $P$. wickerhamii nuclear genome and its comparison to other analyzed genomes are shown in Table 1 . The total assembly size was $16.7 \mathrm{Mbp}$. Gene structure of $P$. wickerhamii, reflected by average gene length, average number of introns/exons per gene, percentage of genes with introns, and mean intergenic length resembled A. protothecoides rather than Helicosporidium sp.
(Table 1). All three algae shared similar GC-rich genomic composition, with higher GC content in exons compared to introns or intergenic regions (Table 1).

As for the other protothecal genomes, that of $P$. wickerhamii appeared to be the most compact, with structure highly similar to $P$. cutis $[11,12]$. Since similar gene structure may suggest the evolutionary proximity between species [19], the data presented herein support close relatedness of $P$. wickerhamii and $P$. cutis.

The evolutionary proximity between $P$. wickerhamii and $P$. cutis was further supported with dendrogram analyses, based on 164 single copy genes shared among Prototheca species (Supplementary Figure S2).

Table 1 Genome annotation statistics of P. wickerhamii, two closely related Chlorellales: A. protothecoides and Helicosporidium sp., and two pathogenic fungi: C. albicans and T. rubrum. Data acquired from GFF files available at NCBI Genome (https://www.ncbi.nlm. nih.gov/genome)

\begin{tabular}{|c|c|c|c|c|c|c|}
\hline \multicolumn{2}{|c|}{ Characteristic } & \multirow{2}{*}{$\begin{array}{l}\text { P. wickerhamii } \\
\text { JADZLO010000000 }\end{array}$} & \multirow{2}{*}{$\begin{array}{l}\text { A. protothecoides } \\
\text { GCA_000733215.1 } \\
\text { (ASM73321v1) }\end{array}$} & \multirow{2}{*}{$\begin{array}{l}\begin{array}{l}\text { Helicosporidium } \\
\text { sp. }\end{array} \\
\text { GCA_ } \\
000690575.1 \\
\text { (Helico_v1.0) }\end{array}$} & \multirow{2}{*}{$\begin{array}{l}\text { C. albicans } \\
\text { GCA_ } \\
000182965.3 \\
\text { (ASM18296v3) }\end{array}$} & \multirow{2}{*}{$\begin{array}{l}\text { T. rubrum } \\
\text { GCA_ } \\
000151425.1 \\
\text { (ASM15142v1) }\end{array}$} \\
\hline Sequencing & $\begin{array}{l}\text { GenBank assembly accession } \\
\text { (NCBI accession no. of assembly) }\end{array}$ & & & & & \\
\hline & Assembly length (Mb) & 16.7 & 22.9 & 12.4 & 14.3 & 22.5 \\
\hline & Conting number & 21 & 1386 & 5666 & 88 & 624 \\
\hline & N50 contig & $1,578,614$ & 35,091 & 3036 & 334,289 & 83,988 \\
\hline & Scaffold number & 21 & 374 & 5666 & 8 & 36 \\
\hline & N50 scaffold & $1,578,614$ & 285,543 & 3036 & $2,231,883$ & $2,156,965$ \\
\hline & Genome coverage (Fold) & ca. $150 \mathrm{x}$ & $145 x$ & $62 x$ & $700 x$ & $\begin{array}{l}\text { 8.19x (7.49x Q > } \\
\text { 20) }\end{array}$ \\
\hline & Sequencing platform & $\begin{array}{l}\text { PacBio; Illumina } \\
\text { MiSeq } 2 \times 300\end{array}$ & $\begin{array}{l}454 \text { GS FLX Titanium; } \\
\text { Illumina HiSeq } 2000\end{array}$ & $\begin{array}{l}\text { Illumina HiSeq; } \\
\text { Illumina GAllx }\end{array}$ & Illumina GAllx & Sanger ABI \\
\hline \multirow[t]{4}{*}{ GC content } & GC content total (\%) & 64.5 & 63.5 & 61.7 & 33.5 & 48.3 \\
\hline & GC content exons (\%) & 68.7 & 68.1 & 66.5 & 35.1 & 51 \\
\hline & $\begin{array}{l}\text { GC content introns (\%) (between } \\
\text { exons) }\end{array}$ & 60.9 & 63 & 58.8 & 29.6 & 43 \\
\hline & $\begin{array}{l}\text { GC content intergenic regions } \\
(\%)\end{array}$ & 58.2 & 58.1 & 58.4 & 30.7 & 45.3 \\
\hline \multirow{11}{*}{$\begin{array}{l}\text { Protein } \\
\text { coding } \\
\text { genes }\end{array}$} & Number of genes & 6081 & 7016 & 6033 & 6263 & 8804 \\
\hline & Average gene length (bp) & 2135 & 2347 & 1031 & 1447 & 1572 \\
\hline & Average exon length (bp) & 288 & 206 & 366 & 1336 & 454 \\
\hline & Average no of exons per gene & 5.1 & 5.7 & 2.2 & 1.1 & 3.1 \\
\hline & Average intron length (bp) & 162.8 & 247.2 & 170.2 & 146.1 & 85.4 \\
\hline & Average no of introns per gene & 4.1 & 4.7 & 1.2 & 0.1 & 2.1 \\
\hline & Genes with introns (\%) & 97.4 & 88.7 & 56.3 & 6.8 & 81.7 \\
\hline & Mean intergenic lenght (bp) & 1734.1 & 2184.4 & 1027 & 937.8 & 1108.1 \\
\hline & Coding sequence ratio $(\%)^{*}$ & 2.7 & 3.26 & 2.06 & 2.28 & 2.56 \\
\hline & Percentage coding & 45.9 & 36.1 & 39.9 & 62.6 & 53.7 \\
\hline & Gene density (gene per Mb) & 365.1 & 306.4 & 486.5 & 438.0 & 391.3 \\
\hline \multicolumn{2}{|l|}{ tRNA genes } & 64 & 71 & 29 & 126 & 100 \\
\hline \multicolumn{2}{|c|}{ Repetitive DNA in genome assembly (\%) } & 2.25 & 1.98 & 1.23 & 4.6 & 1.89 \\
\hline
\end{tabular}

*Coding sequence ratio $=$ assembly length / number of genes * 1000 
A total of 6081 protein-encoding genes were predicted in $P$. wickerhamii, a number similar to Helicosporidium sp. and significantly lower than in A. protothecoides (Table 1). In terms of gene density, defined by the number of genes per Mbp, $P$. wickerhamii genome was similar to $A$. protothecoides (Table 1). The genome of $P$. wickerhamii was predicted to contain 960 less proteincoding genes than similar in size genome of P. stagnora $[11,12]$. It thus seems that the genome size of Prototheca spp. is not associated with coding capacity. However, it cannot be excluded that the high number of genes in previously sequenced Prototheca species might have been overestimated as a consequence of potential fragmentation of genes into multiple individual contigs [20]. This miscalculation is very unlikely for our study, due to complete format of the genome.

Similar to Helicosporidium sp. [21] and A. protothecoides, $P$. wickerhamii genome encoded all tRNAs, except selenocysteine tRNA (Sec-tRNA) (Supplementary Table 1). In eukaryotes, the Sec insertion machinery is widespread in animals and green algae, while being absent in fungi and higher plants [22, 23].

\section{Annotation of repetitive sequences}

The percentage of repetitive sequences (i.e. interspersed low complexity regions and simple repeats - microsatellite regions) within the $P$. wickerhamii genome was comparable to that found in the genome of $A$. protothecoides and higher than in Helicosporidium sp. (Table 1). In all three algae, most of those elements were simple repeats (Supplementary Table 2). The interspersed repeats were extremely rare. Low number of interspersed repeats in small algal genomes is not surprising, since the genome size in eukaryotes is usually positively correlated with the repetitive sequences content [24].

Of note is that $P$. wickerhamii and $A$. protothecoides, in contrast to Helicosporidium sp., encoded Argonaute and Dicer proteins (Supplementary Figure S3), which are involved in silencing of the repetitive elements [25]. Those two proteins are found also in Chlorella, Coccomyxa, and Chlamydomonas genomes [26].

The majority of $P$. wickerhamii interspersed repeats were retroelements of which the long terminal repeat (LTR) elements Gypsy and Copia, predominated (Supplementary Table 2). Those two superfamilies are widely distributed among genomes of plants and fungi [27] including Chlorella variabilis [28] and Candida albicans [29].

Interestingly, an approximately 3-fold reduction of low complexity regions (LCRs) number in $P$. wickerhamii and Helicosporidium was observed, when compared to A. protothecoides (Supplementary Table 2). Lowcomplexity regions are tracts of single amino acids or short amino acid tandem repeats and may play a key role in the emergence of novel genes [30]. Thus, loss of low complexity regions in $P$. wickerhamii may reflect ongoing parasitic genome reduction.

\section{Plastid and mitochondrial genomes}

The mitochondrial (mtDNA) and plastid (ptDNA) genomes of $P$. wickerhamii were comprehensively reported in our previous study [18]. Briefly, the circular mtDNA of $P$. wickerhamii was $53.8 \mathrm{~kb}$ in size, which is similar as in Helicosporidium sp. (49.3 kb), A. protothecoides $(57.2$ $\mathrm{kb})$, and P. xanthoriae $(55.3 \mathrm{~kb})$, but not in other Prototheca spp., whose mtDNAs size was $38.3 \mathrm{~kb}$ (P. ciferrii) and $39.2 \mathrm{kB}$ (P. bovis) (Supplementary Material 1; [18]). This could be explained by more complex intron structure in P. wickerhamii, P. xanthoriae, A. protothecoides, and Helicosporidium sp., when compared to $P$. bovis and $P$. ciferrii, and the presence of additional putative genes [18]. A typical set of 32 mitochondrial protein-coding genes was found in $P$. wickerhamii mtDNA and all but one were present among all the other microalgae studied (Supplementary Material 1; [18]). The exception was the rpl10 gene, encoding for a ribosomal protein L10, found in $P$. ciferrii and $P$. bovis, yet not in $P$. wickerhamii. It has been shown, that during plant evolution, ribosomal protein genes, including rpl10, have been lost from the mitochondrion and transferred to the nucleus [31]. However, this rearrangement was not observed in $P$. wickerhamii.

The circular ptDNA of $P$. wickerhamii sized $48 \mathrm{~kb}$, being larger than ptDNA of $P$. ciferrii, $P$. bovis (ca. 28.7 $\mathrm{kB})$, and Helicosporidium sp. (37.4 kb), but smaller than that of photosynthetic $A$. protothecoides (84.6 kB) (Supplementary Material 1; [18]). The plastid genomes of Prototheca spp. and Helicosporidium sp. did not contain photosystem I and II proteins, cytochrome complex, and all genes for chlorophyll synthesis, when compared with A. protothecoides. In contrast to Helicosporidium sp. and other Prototheca spp., only $P$. wickerhamii and $P$. xanthoriae had all ribosomal proteins maintained. The differences in the gene content among Prototheca spp. may suggest that those algae discarded photosynthesis independently. Plastid genome-based phylogeny provided evidence for at least three independent losses (first in $P$. xanthoriae, the second in the ancestor of $P$. wickerhamii and $P$. cutis, and the third in P. stagnora, P. bovis, and $P$. ciferrii) [18].

\section{Photosynthesis-related genes}

To further look at the $P$. wickerhamii genome reduction in terms of genes involved in photosynthesis, the inventory of proteins unique to plastid-containing organisms, GreenCut2 database was searched against the genome of P. wickerhamii. Overall, it encoded only 10 (13.5\%) out of 74 photosynthesis-related, nuclear genes, predicted by 
the GreenCut2 database (Supplementary Material 2), whereas the photosynthetic $A$. protothecoides and nonphotosynthetic Helicosporidium sp. encoded 54 (73\%) and $8(10.8 \%)$ of those genes, respectively. Eight out of $10(80 \%)$ photosynthetic genes in P. wickerhamii were shared with Helicosporidium sp. Both Helicosporidium and $P$. wickerhamii did not encode proteins of lightharvesting antenna and photosystems I and II. Still, those two algae retained a component of the cytochrome b6/f complex (PetC) and PetF protein involved in the electron transport (Supplementary Material 2). Those data supported that those two non-photosynthetic trebouxiophytes had convergently lost a similar set of genes related to photosynthesis [11].

\section{Functional annotation of the nuclear genes Prediction of domains, sites, repeats, and families among annotated genes}

The Interpro (IPR) resource provides functional analysis of the genes by predicting domains and important sites based on the signatures available in the database. To examine genes using this approach, IPR counts were compared between $P$. wickerhamii, A. protothecoides, and Helicosporidium sp. All these algae had similar percentage of genes in the genome mapped to each term among analyzed domains (Supplementary Material 3 and 4), sites (Supplementary Material 3 and 5), repeats (Supplementary Material 3 and 6), and families (Supplementary Material 3 and 7). Only 40 (1.9\%) out of the total of 2065 Interpro domains were enriched in $P$. wickerhamii when compared to non-pathogenic $A$. protothecoides (with a difference set at $\geq 3$ domains) (Fig. 1). Among those, domains with AAA motif were the most abundant (Fig. 1). The AAA proteins have been associated with various cellular processes including proteolysis, protein folding, membrane trafficking, cytoskeletal regulation, organelle biogenesis, DNA replication, and intracellular motility [32].

\section{Functional analysis of the enzymes and prediction of proteases}

Assigning enzymatic function to the genes was done using IPR signatures. Approximately a fourth (23.3\%) of the genes were associated with enzymatic activity in $P$. wickerhamii, being comparable with Helicospordium sp. (25.5\%), yet distant from $A$. protothecoides, where only $7.1 \%$ of genes had predicted enzyme activity (Supplementary Material 8).

Comparisons with the MEROPS peptidase database revealed that $3.1 \%$ of all genes in P. wickerhamii encoded peptidases (Supplementary Material 9), a number somewhat similar to A. protothecoides (2.8\%) and Helicospordium sp. (2.4\%) (Supplementary Material 10; Fig. 2a). Captivatingly, $P$. wickerhamii and $A$. protothecoides appeared to be particularly well equipped with serine peptidases when compared to Helicospordium sp. (Fig. 2a). Serine peptidases are extremely important in decomposing biomass, and have been frequently characterized in saprotrophs [33].

\section{Possible virulence factors}

To disclose any possible virulence factors in $P$. wickerhamii, a four-step approach, combining (i) comparative genomics, (ii) cross-checking of virulence database (iii) searching for IPR domains overrepresented in P. wickerhamii, and (iv) searching for genes, whose proteins had previously been suggested to be associated with virulence in Prototheca spp.

\section{Comparative genomics - $P$. wickerhamii versus fungal pathogens}

A number of phenotypic features including morphology, antifungal drug susceptibility or opportunistic pathogenicity are shared between $P$. wickerhamii and certain fungi [1]. Thus, $P$. wickerhamii genome was compared with genomes of two model opportunistic fungal pathogens: Candida albicans and Trichophyton rubrum.

As many as $25.3 \%$ of $C$. albicans genes and $20.5 \%$ of $T$. rubrum genes were found in P. wickerhamii (Fig. 2b, Supplementary Material 11). Only 15 genes shared between $P$. wickerhamii and either $C$. albicans or $T$. rubrum had both predicted IPR domain and secretory signal (Table 2). Of those, 3 had glycoside hydrolases (GHs) domain of families 31 (IPR025887), 16 (IPR000757) and 20 (IPR015883). GHs cleave glycosidic bonds in polysaccharides and oligosaccharides and are important virulence factors in many species of bacteria [34] and plant-parasitizing fungi [35]. Notably, GH20 family represents putative virulence factors in oomycetes pathogenic to fish, crustaceans, and mosquitos, but are absent from phytopathogenic oomycetes Phytophthora infestans and Phytophthora nicotianae [36]. Furthermore, genes with saposin B and peptidase S8/S53 (subtilisin) domain were found, which had previously been described as virulence factors in pathogenic fungi, such as a thermodimorphic human pathogen Histoplasma capsulatum [37], Pseudogymnoascus destructans, a psychrophilic fungus that infects hibernating bats [38], and Penicillium expansum, a pathogen of apples and other fruit [39]. Approximately two-thirds $(9 / 15 ; 60 \%)$ of the genes shared between $P$. wickerhamii and either C. albicans or T. rubrum with predicted IPR domain and secretory signal, had previously been characterized in either of the two fungi as related to pathogenicity (Table 2; Supplementary Material 12). Whereas APR1 and PEP1 genes of C. albicans and TERG_00899 of T. rubrum have been associated with penetration and invasion of the host [40-42], ROT2 and SKN1 of C. albicans have 


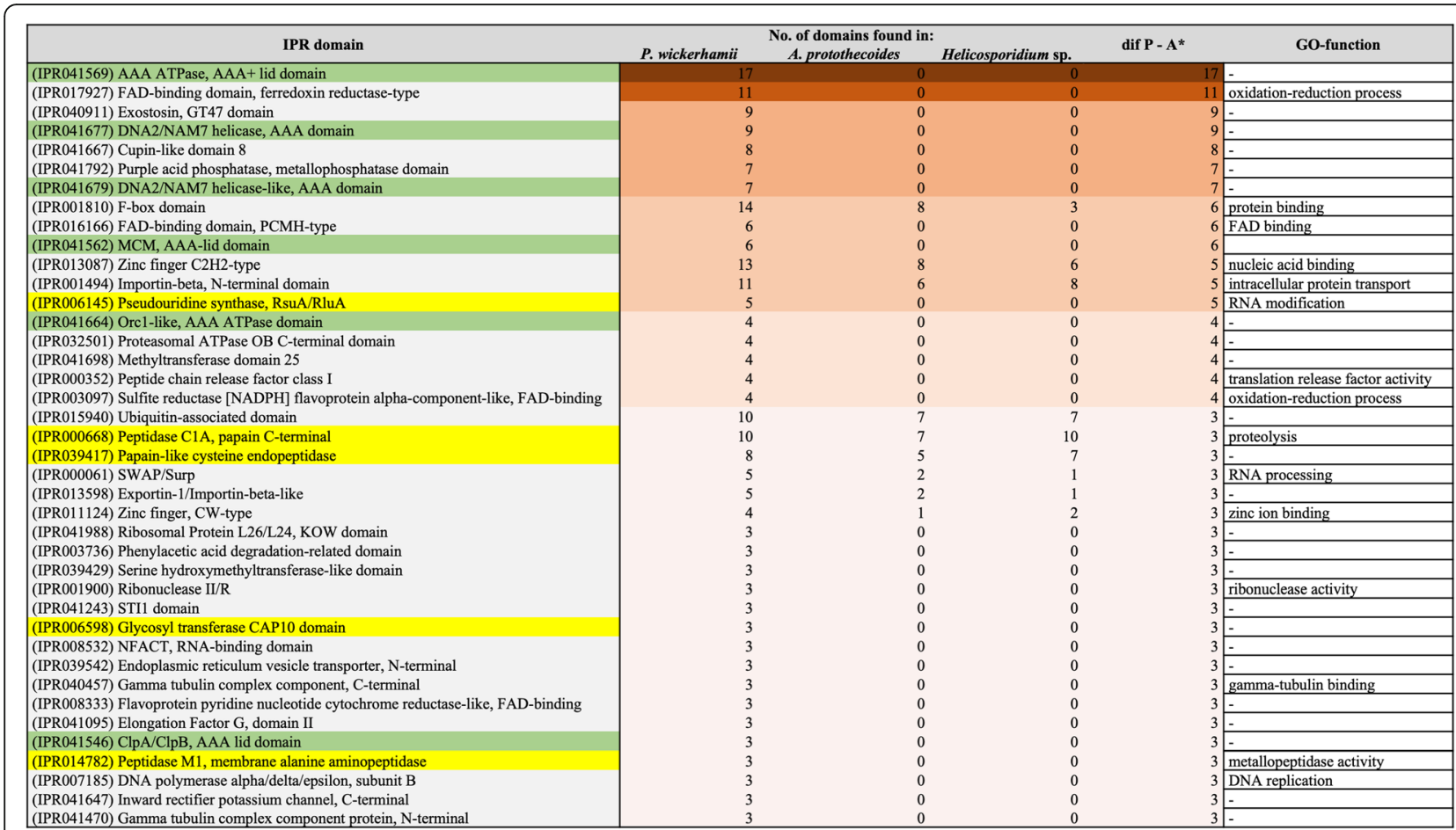

Fig. 1 IPR domains most enriched in P. wickerhamii when compared to nonpathogenic A. protothecoides. Values are colored along a brown (high) to beige (low) color scale, with color scaling relative to the high and low values. Domains characteristic for AAA proteins are marked with green, and potentially involved in pathogenesis in yellow

been linked to cell wall synthesis and mutants at these genes showed decreased in vitro virulence [43, 44]. Other genes found in $P$. wickerhamii were HEX1, GUT2, PNC1, and PDI1. The former allows for utilizing $\mathrm{N}$-acetylglucosamine (GlcNAc) as a carbon source, which is an important virulence attribute of $C$. albicans [45]. Whereas, the other three are related to the adaptive stress response in Candida sp. [46-48].

\section{Comparative genomics - $P$. wickerhamii unique genes}

A total of 1033 genes were found exclusively in $P$. wickerhamii when compared with $A$. protothecoides and Helicosporidium sp. (Fig. 2c; Supplementary Material 13). Seventy-four (7.2\%) contained known IPR domains, making their function predictable. Among genes with recognizable IPR domains were those demonstrated to be involved in response to hypoxia/phagocytosis (IPR001245), toxic substances (IPR004045), and coldinduced thermogenesis (IPR003736) [49-51]. This arsenal might be useful for $P$. wickerhamii to survive different environmental stresses that may confront it, while residing in the host or living saprophytically. Noteworthy, one $P$. wickerhamii unique protein contained LysM domain (IPR018392). This motif has been characterized in fungal plant pathogens, such as Cladosporium fulvum and Magnaporthe oryzae [52]. The LysM domain has also been enriched in several species of dermatophytes, including T. rubrum. It has been, however, unreported in C. albicans, Malassezia globosa, or Pneumocystis jirovecii [53]. The LysM effectors have been hypothesized to protect fungal cells against chitinases and other hydrolytic enzymes [52, 54].

Seventy-seven (7.4\%) of the P. wickerhamii unique proteins contained predicted secretory signal, but only seven $(0.7 \%)$ potentially secreted proteins had assigned IPR domain. Two genes contained domains potentially involved in pathogenesis, i.e. conferring proteolytic (PA domain; IPR003137) and hydrolytic (glycoside hydrolase, family 5; IPR001547) activity.

\section{PHI-database cross-checking}

Pathogen-Host Interaction Database (PHI database) was cross-checked to further identify genes potentially associated with pathogenicity in $P$. wickerhamii. Of the protothecal 593 genes matching a PHI-base entry, $373(62.9 \%)$ had the annotation "reduced virulence" or "loss of pathogenicity", indicating that their role in developing a disease has been experimentally proven (Supplementary Material 14). Among the highly represented $(\geq 2)$ hits in the PHI-base (Fig. 3), two were characterized by the presence of $\mathrm{ABC}$ transporter domain (PHI:1018, PHI:2042 and PHI: 1017, PHI:2067), thereby putatively involved in ATPdependent export of organic anions or drugs from 


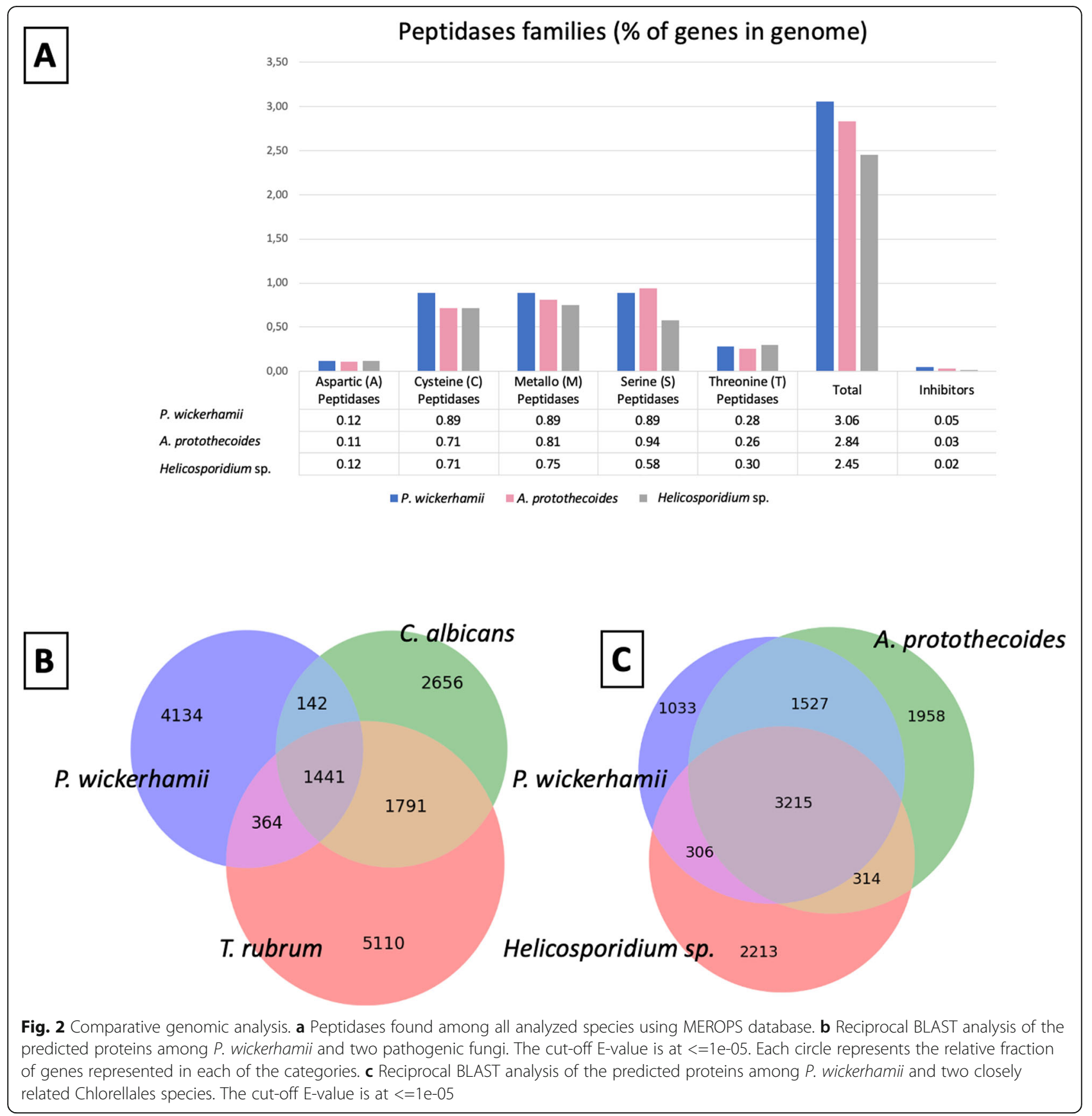

the cytoplasm. Multiple enzymes previously associated with fungal virulence such as oxidoreductases (PHI:2474), kinases (PHI:1193; PHI:2691), and lyases (PHI:305; PHI:2386; PHI:7654) were found. Whereas kinases were demonstrated to be expanded in dermatophytes [53], the importance of lyases for fungal virulence has been evidenced in C. albicans [55] and T. rubrum [56]. There were also as many as 17 hits to a polyketide synthase (PKS) ppsA (PHI:7220). PKSs are secondary metabolites, highly enriched in dermatophytes [53] and involved, for example, in the biosynthesis of melanin in $T$. rubrum during infection [57]. Furthermore, genes involved in host immune evasion in Staphylococcus aureus (PHI:4570) [58] and responsible for the yeast-to-hyphae transition, essential for C. albicans virulence (PHI:211; PHI:2823) were found. Finally, similar to $P$. ciferrii [13], P. wickerhamii encoded hsp 90 and groEL. Both these genes have been associated with the increased virulence in C. albicans [59] and a periodontopathic bacterium Porphyromonas gingivalis [60], respectively. 
Table 2 Secreted proteins shared between P. wickerhamii and either C. albicans or T. rubrum

\begin{tabular}{|c|c|c|c|c|c|}
\hline \multirow[t]{2}{*}{ No. } & \multicolumn{2}{|c|}{ C. albicans } & \multicolumn{2}{|c|}{ T. rubrum } & \multirow[t]{2}{*}{ Interpro (IPR) function } \\
\hline & Orth $^{a}$ & Gene & Orth $^{\mathrm{a}}$ & Gene & \\
\hline 1. & 1 & $\begin{array}{l}\text { CAALFM_CR00690CA; Uncharacterized } \\
\text { protein }\end{array}$ & 1 & $\begin{array}{l}\text { TERG_00664; Uncharacterized } \\
\text { protein }\end{array}$ & Kinase \\
\hline 2. & 0 & - & 1 & $\begin{array}{l}\text { TERG_04330; Uncharacterized } \\
\text { protein }\end{array}$ & Folding of proteins in the endoplasmic reticulum \\
\hline 3. & 0 & - & 1 & $\begin{array}{l}\text { TERG_01168; Uncharacterized } \\
\text { protein }\end{array}$ & Involved in vacuolar sorting \\
\hline 4. & 0 & - & 1 & $\begin{array}{l}\text { TERG_03290; Uncharacterized } \\
\text { protein }\end{array}$ & Involved in nuclear export \\
\hline 5. & 1 & APR1, Proteinase A & 1 & TERG_06704; Vacuolar protease A & Involved in lipid metabolism/virulence \\
\hline 6. & 1 & $\begin{array}{l}\text { GUT2; Glycerol-3-phosphate } \\
\text { dehydrogenase }\end{array}$ & 1 & $\begin{array}{l}\text { TERG_12172; Uncharacterized } \\
\text { protein }\end{array}$ & Oxidoreductase activity \\
\hline 7. & 1 & PEP1; Sortilin & 1 & TERG_02098; Sortilin & Involved in vacuolar protein sorting \\
\hline 8. & 1 & PNC1; Nicotinamidase & 1 & $\begin{array}{l}\text { TERG_06866; Uncharacterized } \\
\text { protein }\end{array}$ & Catalytic activity/hydrolase \\
\hline 9. & 1 & $\begin{array}{l}\text { CAALFM_CR00660WA; Uncharacterized } \\
\text { protein }\end{array}$ & 0 & - & Proteolysis/virulence \\
\hline 10. & 0 & - & 1 & TERG_00899; Neutral ceramidase & $\begin{array}{l}\text { Hydrolyses ceramide to generate sphingosine and } \\
\text { fatty acid }\end{array}$ \\
\hline 11. & 1 & PDI1; Protein disulfide isomerase & 1 & $\begin{array}{l}\text { TERG_04662; Protein disulfide- } \\
\text { isomerase }\end{array}$ & Isomerase activity \\
\hline 12. & 1 & ROT2; Glucan 1\3-alpha-glucosidase & 1 & $\begin{array}{l}\text { TERG_04559; Uncharacterized } \\
\text { protein }\end{array}$ & Glycoside hydrolase \\
\hline 13. & 1 & SKN1; Skn1p & 1 & $\begin{array}{l}\text { TERG_03740; Uncharacterized } \\
\text { protein }\end{array}$ & Glycoside hydrolase \\
\hline 14. & 1 & HEX1; Beta-hexosaminidase & 1 & $\begin{array}{l}\text { TERG_04775; Beta- } \\
\text { hexosaminidase }\end{array}$ & Glycoside hydrolase \\
\hline 15. & 1 & NCR1; Sphingolipid transporter & 1 & $\begin{array}{l}\text { TERG_02938; Uncharacterized } \\
\text { protein }\end{array}$ & Involved in transport of cholesterol \\
\hline
\end{tabular}

${ }^{\mathrm{a} E x i s t e n c e}$ of orthologs in $P$. wickerhamii; 0 - absent; 1 - present

\section{Other possible virulence factors - IPR domains enriched in}

\section{$P$. wickerhamii}

Three peptidase domains, i.e. peptidase $\mathrm{C} 1 \mathrm{~A}$, papain $\mathrm{C}$ terminal (IPR000668), papain-like cysteine endopeptidase (IPR039417), and peptidase M1, membrane alanine aminopeptidase (IPR014782) were expanded in P. wickerhamii when compared to non-pathogenic $A$. protothecoides (Fig. 1). These domains have repeatedly been described as associated with pathogenesis. For instance, C1 peptidases, papain-like cysteine proteases (PLCPs), and alanine aminopeptidases play crucial roles in host/ pathogen interactions in human pathogens, such as parasitic protozoa $[61,62]$ and various plant pathogens $[63,64]$. Among other potential pathogenicity factors, proteins with glycosyl transferase CAP10 domain (IPR006598), known for capsule formation in Cryptococcus neoformans [65], were found in P. wickerhamii. Of particular note is the presence of pseudouridine synthase RsuA/RluA (IPR006145) domain in P. wickerhamii and its lack in Helicosporidium sp. and A. protothecoides (Fig. 1). In vitro transcribed RNAs containing various modified nucleotides, such as pseudouridine suppress the innate immune response in human cells through inactivation of pathogen's RNA recognition by dendritic cells [66]. Captivatingly, none of the secreted endoproteases and exoproteases [67] (e.g. peptidase E, deuterolysin, fungalysin, aspergillopepsin I) from different human pathogenic fungi, including yeasts, molds, and dermatophytes summarized by Monod et al. [67] were present in P. wickerhamii. Accordingly, in P. wickerhamii other enzymes of proteolytic activity have to be involved in the early stages of infection of the host tissues.

\section{Previously described Prototheca sp. virulence factors}

Studies devoted to virulence factors in Prototheca spp. are very few. Irrgang et al. have identified several immunogenic proteins of $P$. ciferrii, $P$. bovis, and P. blaschkeae by assaying sera of Prototheca-infected animals by Western blotting [68, 69]. These finding, paralleled by a study of Murugaiyan et al. [70] have underlined the involvement of the housekeeping heat shock protein 70 (Hsp70) in the P. bovis-induced infections. Furthermore, 


\begin{tabular}{|c|c|c|c|c|c|c|c|c|c|c|c|c|}
\hline No. & PHI-base ID & Protein ID & Gene & Pathogen species & Phenotype & P. wickerhamii & A. protothecoides & $\begin{array}{l}\text { No. of hits in: } \\
\text { Helicosporidium sp. }\end{array}$ & C. albicans & T. rubrum & Gene function & Category \\
\hline 1 & PHI:7220 & P9WOE7 & Ppsa & Mycobacterium tuberculosis & reduced virulence & 17 & 1 & 0 & 0 & 0 & Phthiocerol synthesis PKS & PKS \\
\hline 2 & PHI:211; 6806 & C4YFX2 & Catup1 & Candida albicans & reduced virulence & 5 & 4 & 7 & 1 & 0 & Transcriptional repressor & Signaling/Regulation \\
\hline 3 & PHI:4570 & P02976 & Spa & Staphylococcus aurous & reduced virulence & 5 & 0 & 0 & 0 & 0 & Immunoglobulin G-binding protein A & Pathogenesis \\
\hline 4 & PHI:1018; 2042 & Q3Ү5v5 & $\mathrm{Abc3}$ & Magnaporthe orzzae & loss of pathogenicity & 4 & 4 & 2 & 2 & 2 & ABC Transporter & Transport \\
\hline 5 & PHI:80 & Q00313 & Top1 & Candida albicans & reduced virulence & 3 & 0 & 2 & 1 & 0 & Topoisomerase I & DNARNA associated \\
\hline 6 & PHI:244 & Q8J286 & Clap1 & Colletotrichum indemuthianum & loss of pathogenicity & 3 & 3 & 0 & 2 & 1 & Copper transporting ATPase & Transport \\
\hline 7 & PHI:5240 & $\begin{array}{l}\text { A0A059ZR } \\
97\end{array}$ & Seca & Acinotobacter baumannii & reduced virulence & 2 & 2 & 1 & 0 & 0 & Iron utlization & Transport \\
\hline 8 & $\mathrm{PHI}: 3533$ & A3MZ94 & Lona & Actinobacillus pleuropneumoniae & reduced virulence & 2 & 0 & 2 & 0 & 0 & Lon proteases & Protesases \\
\hline 9 & PHI:2474 & EзP6S0 & Imd1 & Cryptococcus neoformans & reduced virulence & 2 & 1 & 1 & 1 & 1 & Oxidoreductase; GTP Biosynthesis & Biosynthesis \\
\hline 10 & $\mathrm{PH}: 2513$ & E9R5E2 & Gfa1 & Aspergillus fumigatus & loss of pathogenicity & 2 & 1 & 1 & 1 & 1 & Cell wall synthesis & Biosynthesis \\
\hline 11 & PHI:6259 & $\begin{array}{l}\text { AOAOEOSE } \\
\text { E4 }\end{array}$ & Dohn & Fusarium graminearum & reduced virulence & 2 & 2 & 2 & 3 & 1 & Deoxyhypusine hydroxylase & Biosynthesis \\
\hline 12 & PH:3976 & G4NC97 & Moilv6 & Magnaporthe oryzae & loss of pathogenicity & 2 & 2 & 2 & 1 & 1 & Acetolactate synthases & Biosynthesis \\
\hline 13 & PHI:1017; 2067 & G4NDE1 & Abc4 & Magnaporthe oryzae & reduced virulence; loss & 2 & 4 & 2 & 0 & 1 & ABC Transporter & Transport \\
\hline 14 & $\mathrm{PHI}: 2097$ & G4NGP6 & Neo1 & Magnaporthe oryzae & loss of pathogenicity & 2 & 2 & 0 & 1 & 1 & Ca2+ pump & Transport \\
\hline 15 & PH::893 & G4NL37 & Mgg02986 & Magneporthe oryzae & reduced virulence & 2 & 1 & 1 & 2 & 2 & Not assigned & None \\
\hline 16 & PHI:6091 & 11RG99 & Fgvps35 & Fusarium graminearum & reduced virulence & 2 & 2 & 1 & 2 & 1 & Components of retromer & Structural \\
\hline 17 & PHl:1193 & IIRGD6 & Scsky1 & Fusarium graminearum & reduced virulence & 2 & 1 & 1 & 2 & 1 & Protein kinase & Kinases \\
\hline 18 & PHl:1553 & $1157 F 8$ & Gzmyb017 & Fusarium graminearum & reduced virulence & 2 & 2 & 1 & 1 & 1 & Transcription factor & Signaling/Regulation \\
\hline 19 & PHl:2386 & I1S7N4 & Acl1 & Fusarium graminearum & loss of pathogenicity & 2 & 2 & 1 & 0 & 2 & ATP citrate lyase & Lyases \\
\hline 20 & PHI:65 & 014435 & Cpgb-1 & Cryphonectria parasitica & reduced virulence & 2 & 0 & 0 & 0 & 0 & $G$ beta protein subunit & Signaling/Regulation \\
\hline 21 & PHI:6268 & P00722 & Lacz & Escherichia coli & reduced virulence & 2 & 2 & 0 & 0 & 0 & Beta-galactosidase & Biosynthesis \\
\hline 22 & PHI:305 & РОСт06 & |c|1 & Magnaporthe oryzae & reduced virulence & 2 & 0 & 0 & 0 & 0 & Isocitrate Iyase & Lyases \\
\hline 23 & PHI:22 & P49606 & Uac1 & Ustilago maydis & loss of pathogenicity & 2 & 0 & 0 & 0 & 0 & Adenylate cyclase & Signaling/Regulation \\
\hline 24 & PH:1671 & Q4HWE2 & Gzcchc011 & Fusarium graminearum & reduced virulence & 2 & 0 & 1 & 1 & 1 & Transcription factor & Signaling/Regulation \\
\hline 25 & PH::7654 & Q4WJ777 & Arob & Aspergillus fumigatus & reduced virulence & 2 & 1 & 1 & 1 & 1 & Chorismate synthase & Lyases \\
\hline 26 & PHI: 2530 & Q4WKG5 & Tub1 & Aspergillus fumigatus & loss of pathogenicity & 2 & 2 & 1 & 1 & 1 & $\beta$-tubulin housekeeping gene & Biosynthesis \\
\hline 27 & PHI:358 & Q6SSJ3 & IIv2 & Cryptococcus neoformans & loss of pathogenicity & 2 & 0 & 1 & 0 & 0 & Acetolactate synthase & Biosynthesis \\
\hline 28 & PHI:2991 & Q52G60 & Mgg01426 & Magnaporthe oryzae & reduced virulence & 2 & 0 & 0 & 0 & 0 & Transcription factor & Signaling/Regulation \\
\hline 29 & PHI:2823 & Q59×38 & Pes 1 & Candida albicans & reduced virulence & 2 & 2 & 1 & 1 & 0 & Cell cycle control & Signaling/Regulation \\
\hline 30 & PHI:3287 & Q6FSR7 & Cgvps34 & Candida glabrata & reduced virulence & 2 & 2 & 1 & 0 & 1 & Not assigned & None \\
\hline 31 & PHI:2691 & Q6FUl3 & Ire1 & Candida glabrata & reduced virulence & 2 & 1 & 0 & 2 & 0 & Transmembrane kinase & Kinases \\
\hline 32 & PHI: $824 ; 6838$ & Q75WC5 & Gyra & Burkholderia glumae & $\begin{array}{l}\text { resistance to chemical; } \\
\text { reduced virulene }\end{array}$ & 2 & 0 & 0 & 0 & 1 & DNA gyrase & DNA/RNA associated \\
\hline 33 & PH: 3878 & Q8ZLT3 & Pnp & Salmonella enterica & reduced virulence & 2 & 0 & 0 & 0 & 0 & RNA processing and degradation & DNA/RNA associated \\
\hline 34 & PHI:220 & Q9HFU4 & Man1 & Cryptococcus neoformans & reduced virulence & 2 & 1 & 1 & 1 & 1 & Phosphomannose isomerase & Biosynthesis \\
\hline 35 & PHI:2108 & Q9UWF0 & Cam & Magnaporthe oryzae & $\begin{array}{l}\text { reduced virulence; loss } \\
\text { of pathogenicity }\end{array}$ & 2 & 2 & 1 & 1 & 1 & Not assigned & None \\
\hline 36 & PHI:7792 & S8F4SO & Tgdegp & Toxoplasma gondii & reduced virulence & 2 & 2 & 2 & 0 & 0 & Serine protease, thoptry protein & Protesases \\
\hline 37 & PHI:5277 & S8F6T7 & Asp5 & Toxoplasma gondii & reduced virulence & 2 & 1 & 1 & 0 & 0 & Aaspartyl protease & Protesases \\
\hline
\end{tabular}

Fig. 3 Highly represented $(\geq 2)$ hits in PHI-base found in P. wickerhamii and their abundance in other analyzed genomes. Various row colors represent different functional categories. No. of hits are colored along a red (high) to yellow (low) color scale, with color scaling relative to the high and low values. When no of hits $=0$, green color was used

among the immunodominant proteins identified by Irrgang et al. [68], elongation factor 1- $\alpha$, glyceraldehyde-3phosphate dehydrogenase, ATPase, and malate dehydrogenase exhibited differential expression profiles between pathogenic and non-pathogenic Prototheca species [63, 64, 70]. Genes coding for those 84 differentially expressed proteins, were searched against $P$. wickerhamii genome. All but 14 (70 or $83.3 \%$ ) were found in the $P$. wickerhamii genome (Supplementary Material 15). Among them were ATPase, malate dehydrogenase, EF 1- $\alpha$, and glyceraldehyde-3-phosphate dehydrogenase. Strikingly, Hsp70 protein (GenBank ID: E1Z7R4) was absent in P. wickerhamii (Supplementary Material 15). This may relate to the host preference of different Prototheca species. The Hsp70-harboring $P$. bovis affects mostly dairy cattle, while Hsp70-defficient $P$. wickerhamii is largely a human pathogen.

\section{Conclusions}

To conclude, this paper provides a first insight into the genome of $P$. wickerhamii and discovers its general structural and functional features. The key findings can be summarized in five points. First, $P$. wickerhamii genome was the smallest among all protothecal genomes sequenced so far. Only an obligatorily pathogenic alga Helicosporidium sp. did display a more compact genome. Second, the structure of $P$. wickerhamii genome highly resembled that of closely related non-pathogenic green alga $A$. protothecoides. However, a high genome reduction was observed, as evidenced by the loss of lowcomplexity regions and photosynthesis-related genes. Third, $P$. wickerhamii showed a large battery of enzymes, possibly facilitating the adaptation of the alga to different ecological niches, including tissues of the parasitized host. Fourth, P. wickerhamii encoded numerous genes, which had previously been described as related to pathogenicity in fungi. Neither of these virulence factors, however, did represent the iconic fungal secreted endo- and exoproteases. Fifth, several new candidates for $P$. wickerhamii-specific virulence factors were described. Among these, were genes proven to affect the outcome of pathogen-host interactions reported in PHI-database, as well as $P$. wickerhamii unique genes with recognizable IPR domains involved in pathogenicity. Further experimental studies involving real-time PCR experiments and in vitro/vivo pathogenesis models are required to confirm role of these genes in $P$. wickerhamii virulence. 


\section{Methods}

Strain

P. wickerhamii ATCC 16529 type strain, initially described by Tubaki \& Soneda [71], purchased from American Type Culture Collection, and preserved in the Department of Medical Microbiology, Faculty of Biology, University of Warsaw collection, was used in this study. The strain was originally isolated from household plumbing in Peoria, IL (USA). It was stored in Viabank ${ }^{\text {тм }}$ cryopreservative vial (Medical Wire \& Equipment Co Ltd., Corsham, the UK), at $-70{ }^{\circ} \mathrm{C}$ and revived by streaking a loopful $(10 \mu \mathrm{L})$ of the frozen culture on a Yeast Peptone Dextrose (YPD) (Difco, USA) agar plate and incubating at $37^{\circ} \mathrm{C}$ aerobically for $72 \mathrm{~h}$.

Cells of $P$. wickerhamii were then harvested from a single colony and grown in a $100 \mathrm{~mL}$ of YPD broth at $37^{\circ} \mathrm{C}(200 \mathrm{rpm})$ until the absorbance at A600 reached approx. 5.0 (ca. $6.5 \times 10^{5} \mathrm{CFU}, 72 \mathrm{~h}$ ).

\section{Genomic DNA extraction}

Genomic DNA was isolated as described before [72] with a method based on three-pronged approach for whole cell lysis, i.e. mechanical (glass beads), enzymatic (Proteinase K) and surfactant-based (Triton-X100, SDS, and $\mathrm{CTAB})$, disruption methods.

\section{Genome sequencing and assembly}

The genome of $P$. wickerhamii was sequenced using a combination of Illumina (Illumina Inc., USA) and PacBio (Pacific Biosciences, USA) technologies.

The Illumina paired-end sequencing library construction was performed with $1 \mu \mathrm{g}$ of post-nebulized DNA extract and the KAPA Library Preparation Kit reagents (KAPA Biosystems, USA), according to manufacturer's instructions. The library was pooled and sequenced on a MiSeq platform using the 600-cycle MiSeq reagent Kit v.3 (Illumina, USA).

The PacBio libraries were constructed using approximately $20 \mu \mathrm{g}$ of genomic DNA that was mechanically sheared to a size of $20 \mathrm{~kb}$, using a Covaris gTube (Covaris, USA). Samples were then prepared by ligation of hairpin adaptors at both ends of the DNA fragment using the PacBio DNA template preparation kit 2.0 (Pacific Biosciences, USA). Libraries were purified using Agencourt AMPure beads (Beckman Coulter, USA) to remove fragments shorter than ca. $1.5 \mathrm{~kb}$ and sizeselected using the BluePippin preparation system (Sage Science, USA) with a minimum cutoff of $7 \mathrm{~kb}$. The sheared DNA and final library were characterized for size distribution using an Agilent Bioanalyzer 2100 (Agilent Technology, USA) along with a DNA12000 chip (Agilent Technology, USA). Single Molecule, Real-Time (SMRT) sequencing was carried out on the PacBio RS II using standard protocols (Pacific Biosciences, USA).
Once obtained, Illumina data were filtered by reads quality (> 20 qval) using FastaX [73], and the remaining sequencing adaptors were removed by Cutadapt [74]. PacBio long reads were filtered by length $(>1 \mathrm{~kb})$ and quality (> 15 qval) using NanoFilt [75] and assembled de novo with wtdbg2 software (default parameters) [76]. Polishing long read assemblies with Illumina data was done with Pilon [77]. For further analyses the SeqMan (DNAStar, USA) and CLCBio Genomic Workbench pipeline for NGS (CLCBio, Denmark) were used.

\section{RNA sequencing and assembly}

RNA samples for transcriptome analysis were extracted in duplicate from single culture condition at one timepoint as described below. Cells of $P$. wickerhamii for RNA isolation were picked from a single colony and grown in a $50 \mathrm{~mL}$ of YPD broth at $37^{\circ} \mathrm{C}$ with shaking (200 rpm) until the absorbance at A600 reached approx. 5.0 (ca. $6.5 \times 10^{5} \mathrm{CFU}, 72 \mathrm{~h}$ ). Cells in the stationary phase were harvested by centrifugation $(5000 \mathrm{rpm})$, and after decanting the medium, they were resuspended in StayRNA reagent (A\&A Biotechnology, Poland), aliquoted into two equal portions and stored at $-70^{\circ} \mathrm{C}$ until used.

RNA for transcriptome analysis was isolated from both cell portions using Total RNA kit (A\&A Biotechnology, Poland), following manufacturer's instructions, with an additional step of cell disruption. This was done by pulverization at $20 \mathrm{~Hz}$ for $15 \mathrm{~min}$, using glass beads and TissueLyser II apparatus (Qiagen, Germany). RNA degradation and genomic DNA contamination were monitored on $1 \%$ agarose gels. Samples were then treated with the RNase-free DNase (A\&A Biotechnology, Poland) to remove any contaminating genomic DNA. RNA purity was checked using a NanoPhotometer ${ }^{\ominus}$ spectrophotometer (IMPLEN, USA) and the concentration was measured using a Qubit $^{\oplus}$ RNA Assay Kit with a Qubit $^{\oplus}$ 2.0 Flurometer (Thermo Fisher Scientific, USA). RNA integrity was assessed using the RNA 6000 Nano Assay Kit of the Bioanalyzer 2100 system (Agilent Technologies, USA). Finally, a total of $5 \mu \mathrm{g}$ of RNA was used as input material for the libraries preparations. Sequencing libraries were generated using a Kapa Stranded mRNA Library Prep Kit for Illumina (KAPA Biosystems, USA) according to the producer's protocol. The purified libraries were checked for quality and quantity using the Agilent 2100 Bionalyzer, Qubit ${ }^{\top} 2.0$ (Thermo Fisher Scientific, USA) and KAPA Library Quantification kit (Roche, Switzerland) and subsequently sequenced on a MiSeq instrument (Illumina, USA) with $2 \times 75$-bp paired-end reads.

The obtained reads were subjected to quality control and soft trimming using FastQC v0.11.6 and Trimmomatic v0.39. Adaptors sequences were removed 
alongside with low quality ( $>20$ qval) and short ( $>15 \mathrm{bp}$ ) reads. Remaining sequences were used for transcriptome assembly by Trinity v2.1.1 with default settings for unguided assembly. Filtered reads were also mapped against created genome assembly using STAR v2.6.1a, followed by Cufflinks v2.2.1 [78] transcripts assembly. The fasta sequences of the transcripts was obtained from by bedtools v2.27.1. Downstream analysis and comparisons of collected transcripts, their isoforms and annotation were handled by custom bash and python scripts.

\section{Genome statistics}

Genome statistics was calculated using GFF files obtained from NCBI Genome database (as referenced in Table 1; https://www.ncbi.nlm.nih.gov/genome; accessed 08.2018), and processed with BUSCO v3 [79] and QUAST [80]. If necessary, an in-house python script was implemented (available at https://github.com/ henryk69/prototheca).

\section{Gene annotation}

Genome completeness was assessed using BUSCO v3 with eukaryota_odb9 database [79]. Scaffold sequences were masked with RepeatMasker v4.0.8 using the Viridiplantae section [81]. Gene prediction and annotation was performed using the MAKER v2 annotation pipeline [82]. For $a b$ initio gene prediction, a combination of predictions from GeneMark-ES v4.10 [83] and AUGUSTUS v3.2.3 [84] trained with BRAKER v2.0 [85] using genome and data derived from RNA-sequencing was used. To generate protein-based evidence Expressed Sequence Tags (ESTs), a database was prepared. A total of 34,771 sequences from the Chlorellales family i.e. Helicosporidium sp., A. protothecoides, Parachlorella kessleri, Chlorella vulgaris, Chlorella variablilis and Chlorella pyrenoidosa, and 6805 sequences deposited for P. wickerhamii (derived from the sequencing of plastid and mitochondrial genome) available at NCBI database were included. EST, RNA-sequencing data and ab initio gene predictors were all used with the MAKER pipeline to iteratively obtain the final gene annotations.

tRNAscan v1.4 [86] was used to predict tRNA genes.

RepeatMasker 4.0 with RepBase was used to identify and mask interspersed low-complexity regions as well as simple repeats (micro-satellites) in the DNA [87]. The Viridiplantae dataset was used to define transposable elements present in the analyzed Chlorellales genomes.

All sequence similarity was assessed using BLAST v2.2.24 [88]) with E-value cutoff 1e-10. Sequence alignments were prepared using Exonerate [89].

GeneOntology annotations were obtained from Blast2GO [90]. Blast2GO was also used for InterProScan [91] domain annotations. GreenCut [92], PHI-base [93] and Merops [94] databases were searched with a reciprocal procedure using BLASTP with E-value 1e-10. Dicer and Argonaute viridiplantae proteins were obtained from UniprotKB [95] database.

Comparative genomics assessment was done using a reciprocal BLASTP procedure used in [96] to identify putative orthologous proteins between all three Chlorellales and two fungi genomes based on one-to-one reciprocal best BLASTP hits. All reciprocal BLASTP searches between were performed with an E-value cutoff of 1e10 and identified protein pairs which were reciprocally one another's top BLASTP hit and that occurred once and only once in each proteome query. All obtained annotation and protein similarity results were assessed with in-house built python scripts using standard pandas, numpy, matplotlib, seaborn, and other libraries (available at https://github.com/henryk69/prototheca).

Genes coding for 84 differentially expressed proteins between pathogenic and non-pathogenic Prototheca species $[63,64,70]$ were used as identifiers for UniprotKB database. All 84 proteins were obtained in their cannonical form. Reciprocal BLAST procedure was done with Evalue threshold set to e-10 and at least $40 \%$ sequence similarity to ensure genuine resemblance between the $P$. wickerhamii proteome and the 84 proteins.

\section{Phylogenetic analysis}

Phylogenetic tree was prepared using single copy conserved genes retrieved by BUSCO with eucaryotic_odb9 gene dataset. A total of 164 universal single copy genes were shared among all 5 Prototheca species, with available WGS data ([11-13]; this manuscript).

Protein sequences (products of the 164 single copy genes) were aligned with MAFFT (v7.475) [97] with default parameters and trimmed with trimAl (v. 1.2rev59) [98] with the strictplus option enabled. To generate the phylogenetic tree from the concatenated alignment RAxML (v8.2.12) [99] was used with options: rapid bootstrap analysis ( $-\mathrm{f}$ a), 100 boostrap samples $(-\mathrm{N} 100)$ and GAMMA model of rate heterogeneity with automatically chosen best protein substitution model ( $\mathrm{m}$ PROTGAMMAAUTO). EvolView [100] was used for tree visualization.

\section{Supplementary Information}

The online version contains supplementary material available at https://doi. org/10.1186/s12864-021-07491-8

Additional file 1: Supplementary Figure S1. Completeness of the analyzed genomes assessed with BUSCO. The red, yellow, dark blue and light blue bar chart shows the \% of missing (M), fragmented (F), complete (C) and duplicated (D), complete (C) and single copy (S) genes in the assemblies, respectively.

Additional file 2: Supplementary Figure S2. Maximum likelihood $(\mathrm{ML})$ phylogenetic tree based on the 164 universal single copy genes shared among Prototheca species. The phylogenetic tree shows, that $P$. 
wickerhamii is closely related to $P$. cutis and more distantly to $P$. stagnora. $P$. bovis and $P$. ciferrii seem evolutionary closer to each other than to $P$. wickerhamii. The presented herein architecture is the same for all 100 bootstrapped trees.

Additional file $\mathbf{3}$ Supplementary Figure $\mathbf{3 3}$. Dicer and Argonuate proteins found within P. wickerhamii (A) and A. protothecoides (B) genomes. In $P$. wickerhamii Dicer protein resembles the DCL2 from $A$. thaliana (e-value $=5.75 \mathrm{e}-60$; sequence similarity: $>56 \%$ ) whereas the Argonaute protein - AGO_10 from A. thaliana (e-value $=8 \mathrm{e}-103,>45 \%$ similarity).

Additional file 4: Supplementary Table 1. List of tRNA gene sequences found in the P. wickerhamii and A. protothecoides.

Additional file 5: Supplementary Table 2. Repetitive DNA elements found in the P. wickerhamii, two closely related Chlorellales: A. protothecoides and Helicosporidium sp., and two pathogenic fungi: $C$. albicans and T. rubrum

Additional file 6: Supplementary Materials.

\section{Acknowledgements}

Not applicable.

\section{Authors' contributions}

Z.B. performed culturing, analyzed the data and wrote the article, provided the funding; P.S. provided genome annotation and analyzed the data; R.G. performed genome sequencing (Illumina \& RNA-sequencing), provided plastid \& mitochondrial annotation; J.G. performed genome sequencing (Illumina \& RNA-sequencing); A.G. analyzed RNA-sequencing data; J.J.P. performed genome sequencing (PacBio); H.P. performed genome sequencing (PacBio); T.J. conceptualized and supervised the study, provided the funding, critical revision. The author(s) read and approved the final manuscript.

\section{Funding}

The study was financed by the National Science Centre grants «PRELUDIUM» (2013/09/N/NZ2/00248) and «SONATA» (2014/15/D/NZ7/01797).

\section{Availability of data and materials}

This Whole Genome Shotgun project of P. wickerhamii has been deposited at DDBJ/ENA/GenBank under the accession JADZLO000000000. The version described in this paper is version JADZLO010000000.

All in-house python scripts are available at https://github.com/henryk69/ prototheca.

Furthermore, the datasets supporting the conclusions of this article are available as Supplementary Tables $1 \& 2$ and Supplementary Material.

\section{Declarations}

Ethics approval and consent to participate

Not applicable.

\section{Consent for publication}

Not applicable.

\section{Competing interests}

Not applicable.

\section{Author details}

${ }^{1}$ Department of Medical Microbiology, Institute of Microbiology, Faculty of Biology, University of Warsaw, I. Miecznikowa 1, 02-096 Warsaw, Poland. ${ }^{2}$ Department of Systems Biology, University of Warsaw, I. Miecznikowa 1, 02-096 Warsaw, Poland. ${ }^{3}$ Department of Bioinformatics, Institute of Biochemistry and Biophysics, Polish Academy of Sciences, A. Pawińskiego 5a, 02-106 Warsaw, Poland. ${ }^{4}$ DNA Sequencing and Synthesis Facility, Institute of Biochemistry and Biophysics, Polish Academy of Sciences, A. Pawińskiego 5a, 02-106 Warsaw, Poland. ${ }^{5}$ Museum and Institute of Zoology, Polish Academy of Sciences, Wilcza 64, 00-679 Warsaw, Poland.
Received: 9 October 2020 Accepted: 26 February 2021

Published online: 09 March 2021

\section{References}

1. Jagielski T, Lagneau PE. Protothecosis. A pseudofungal infection. J Mycol Méd. 2007:17:261-70.

2. Lass-Flörl C, Mayr A. Human protothecosis. Clin Microbiol Rev. 2007;20:23042.

3. Pal M, Kenubih A, Mammo B. Chlorellosis: an emerging algal disease of animals and humans. Indian J Comp Microbiol Immunol Infect Dis. 2015;36: $1-6$.

4. Jagielski T, Bakula Z, Gawor J, Maciszewski K, Dyląg M, Nowakowska J, Gromadka R, Karnkowska A. The genus Prototheca (Trebouxiophyceae, Chlorophyta) revisited: implications from molecular taxonomic studies. Alg Res. 2019:43:101639.

5. Pore RS. Prototheca Krüger. In: Kurtzmann CP, Fell JW, editors. The yeasts. A taxonomic study. New York: Elsevier; 2011. p. 2071-80.

6. Krüger W. Kurze Charakteristik einiger niederer Organismen im Saftflüsse der Laubbaume. Hedwigia. 1894:33:241-66.

7. Yan D, Wang Y, Murakami T, Shen Y, Gong J, Jiang H, Smith DR, Pombert JF, Dai J, Wu Q. Auxenochlorella protothecoides and Prototheca wickerhamii plastid genome sequences give insight into the origins of nonphotosynthetic algae. Sci Rep. 2015;25:14465.

8. Kunthiphun S, Endoh R, Takashima M, Ohkuma M. Tanasupawat, S. \& Savarajara, A. Prototheca paracutis sp. nov., a novel oleaginous achlorophyllous microalga isolated from a mangrove forest. Mycoscience. 2019:60:165-9.

9. Davies RR, Spencer H, Wakelin PO. A case of human protothecosis. Trans R Soc Trop Med Hyg. 1964;58:448-51.

10. Todd JR, Matsumoto T, Ueno R, Murugaiyan J, Britten A, King JW, Odaka Y, Oberle A, Weise C, Roesler U, Pore RS. Medical phycology 2017. Med Mycol. 2018;56:188-204.

11. Suzuki S, Endoh R, Manabe Rl, Ohkuma M, Hirakawa Y. Multiple losses of photosynthesis and convergent reductive genome evolution in the colourless green algae Prototheca. Sci Rep. 2018;17:940.

12. Severgnini M, Lazzari B, Capra E, Chessa S, Luini M, Bordoni R, Castiglioni B, Ricchi M, Cremonesi P. Genome sequencing of Prototheca zopfii genotypes 1 and 2 provides evidence of a severe reduction in organellar genomes. Sci Rep. 2018;8:14637.

13. Zeng X, Kudinha T, Kong F, Zhang QQ. Comparative genome and transcriptome study of the gene expression difference between pathogenic and environmental strains of Prototheca zopfii. Front Microbiol. 2019;7:443.

14. Wolff $G$, Kuck $U$. The structural analysis of the mitochondrial SSU rRNA implies a close phylogenetic relationship between mitochondria from plants and from the heterotrophic alga Prototheca wickerhamii. Curr Genet. 1990:17:347-51.

15. Wolff G, Burger G, Lang BF, Kück U. Mitochondrial genes in the colourless alga Prototheca wickerhamii resemble plant genes in their exons but fungal genes in their introns. Nucleic Acids Res. 1993;21:719-26.

16. Wolff G, Plante I, Lang BF, Kück U, Burger G. Complete sequence of the mitochondrial DNA of the chlorophyte alga Prototheca wickerhamii. Gene content and genome organization. J Mol Biol. 1994;18:75-86.

17. Wolff G, Kück U. Transcript mapping and processing of mitochondrial RNA in the chlorophyte alga Prototheca wickerhamii. Plant Mol Biol. 1996;30:57795.

18. Bakuła Z, Gromadka R, Gawor J, Siedlecki P, Pomorski JJ, Maciszewski K, Gromadka A, Karnkowska A, Jagielski T. Sequencing and analysis of the complete organellar genomes of Prototheca wickerhamii. Front Plant Sci. 2020. https://doi.org/10.3389/fpls.2020.01296.

19. Li XQ, Du D. Variation, evolution, and correlation analysis of $C+G$ content and genome or chromosome size in different kingdoms and phyla. PLoS One. 2014;9:e88339.

20. Denton JF, Lugo-Martinez J, Tucker AE, Schrider DR, Warren WC, Hahn MW. Extensive error in the number of genes inferred from draft genome assemblies. Plos Comput Biol. 2014;10:e1003998.

21. Pombert JF, Blouin NA, Lane C, Boucias D, Keeling PJ. A lack of parasitic reduction in the obligate parasitic green alga Helicosporidium. Plos Genet. 2014;10:e1004355.

22. Turanov AA, Xu X-M, Carlson BA, Yoo M-H, Gladyshev VN, Hatfield DL. Biosynthesis of selenocysteine, the 21st amino acid in the genetic code, and a novel pathway for cysteine biosynthesis. Adv Nutr. 2011;2:122-8. 
23. Santesmasses D, Mariotti M, Guigó R. Computational identification of the selenocysteine tRNA (tRNASec) in genomes. Plos Comput Biol. 2017;13: e1005383.

24. Gregory TR. Synergy between sequence and size in large-scale genomics. Nat Rev Genet. 2005;6:699-708.

25. Fang X, Qi Y. RNAi in plants: an Argonaute-centered view. Plant Cell. 2016; 28:272-85.

26. Cerutti H, Ma X, Msanne J, Repas T. RNA-mediated silencing in algae: biological roles and tools for analysis of gene function. Eukaryot Cell. 2011; 10:1164-72

27. Llorens C, Futami R, Covelli L, Domínguez-Escribá L, Viu JM, Tamarit D. The Gypsy Database (GyDB) of mobile genetic elements: release 2.0. Nuc Acids Res. 2011;39:D70-4.

28. Blanc G, Duncan G, Agarkova I, Borodovsky M, Gurnon J, Kuo A, Lindquist E, Lucas S, Pangilinan J, Polle J, Salamov A, Terry A, Yamada T, Dunigan DD, Grigoriev IV, Claverie JM, Van Etten JL. The Chlorella variabilis NC64A genome reveals adaptation to photosymbiosis, coevolution with viruses, and cryptic sex. Plant Cell. 2010;22:2943-55.

29. Zhang $L$, Yan $L$, Jiang J, Wang $Y$, Jiang $Y$, Yan $T$, Cao $Y$. The structure and retrotransposition mechanism of LTR-retrotransposons in the asexual yeast Candida albicans. Virulence. 2014;5:655-64.

30. Toll-Riera M, Radó-Trilla N, Martys FM, Albà M. Role of low-complexity sequences in the formation of novel protein coding sequences. Mol Biol and Evol. 2012;29:883-6.

31. Mower JP, Bonen L. Ribosomal protein L10 is encoded in the mitochondrial genome of many land plants and green algae. BMC Evol Biol. 2009;9:265.

32. Tucker PA, Sallai L. The AAA superfamily - a myriad of motions. Curr Opin Struct Biol. 2007;17:641-52

33. da Silva RR. Commentary: fungal lifestyle reflected in serine protease repertoire. Front Microbiol. 2018:9:467.

34. Frederiksen RF, Paspaliari DK, Larsen T, Storgaard BG, Larsen MH, Ingmer $H$, Palcic MM, Leisner JJ. Bacterial chitinases and chitin-binding proteins as virulence factors. Microbiology. 2013;159:833-47.

35. Parrent $J$, James TY, Vasaitis R, Taylor AF. Friend or foe? Evolutionary history of glycoside hydrolase family 32 genes encoding for sucrolytic activity in fungi and its implications for plant-fungal symbioses. BMC Evol Biol. 2009;9: 148.

36. Olivera IE, Fins KC, Rodriguez SA, Abiff SK, Tartar JL, Tartar A. Glycoside hydrolases family $20(\mathrm{GH} 20)$ represent putative virulence factors that are shared by animal pathogenic oomycetes, but are absent in phytopathogens. BMC Microbiol. 2016;6:232.

37. Beck MR, Dekoster GT, Cistola DP, Goldman WE. NMR structure of a fungal virulence factor reveals structural homology with mammalian saposin B. Mol Microbiol. 2009;72:344-53.

38. Pannkuk EL, Risch TS, Savary BJ. Isolation and identification of an extracellular subtilisin-like serine protease secreted by the bat pathogen Pseudogymnoascus destructans. PLoS One. 2015;18:e0120508.

39. Levin E, Raphael G, Ma J, Ballester AR, Feygenberg O, Norelli J, Aly R, Gonzalez-Candelas L, Wisniewski M, Droby S. Identification and functional analysis of NLP-encoding genes from the postharvest pathogen Penicillium expansum. Microorganisms. 2019;15:175.

40. Kvaal, S., Lachke, T., Srikantha, K., Daniels, J. \& McCoy, D.R. Soll. Misexpression of the opaque phase-specific gene PEP1 (SAP1) in the white phase of Candida albicans confers increased virulence in a mouse model of cutaneous infection. Infect Immun. 67, 6652-6662 (1999).

41. Giddey K, Monod M, Barblan J, Potts A, Waridel P, Zaugg C, Quadroni M. Comprehensive analysis of proteins secreted by Trichophyton rubrum and Trichophyton violaceum under in vitro conditions. J Proteome Res. 2007;6: 3081-92.

42. Saroukolaei AS, Ghabaee M, Shokri H, Khosravi A, Badiei A. Evaluation of APR1 gene expression in Candida albicans strains isolated from patients with multiple sclerosis. Jundishapur J Microbiol. 2016;9:e33292.

43. Mora-Montes HM, Ponce-Noyola P, Villagómez-Castro JC, Gow NA, FloresCarreón A, López-Romero E. Protein glycosylation in Candida. Future Microbiol. 2009;4:1167-83.

44. Han Q, Wang N, Yao G, Mu C, Wang Y, Sang J. Blocking B-1,6-glucan synthesis by deleting KRE6 and SKN1 attenuates the virulence of Candida albicans. Mol Microbiol. 2019;111:604-20.

45. Ruhela D, Kamthan M, Saha P, Majumdar SS, Datta K, Abdin MZ, Datta A. In vivo role of Candida albicans $\beta$-hexosaminidase (HEX1) in carbon scavenging. Microbiol Open. 2015;4:730-42.
46. Gergondey R, Garcia C, Serre V, Camadro JM, Auchère F. The adaptive metabolic response involves specific protein glutathionylation during the filamentation process in the pathogen Candida albicans. Biochim Biophys Acta. 2016;1862:1309-23.

47. Roetzer A, Gregori C, Jennings AM, Quintin J, Ferrandon D, Butler G, Kuchler K, Ammerer G, Schüller C. Candida glabrata environmental stress response involves Saccharomyces cerevisiae Msn2/4 orthologous transcription factors. Mol Microbiol. 2008;69:603-20.

48. Tillmann AT, Strijbis K, Cameron G, Radmaneshfar E, Thiel M, Munro CA, MacCallum DM, Distel B, Gow NA, Brown AJ. Contribution of Fdh3 and GIr1 to glutathione redox state, stress adaptation and virulence in Candida albicans. PLoS One. 2015;10:e0126940.

49. Dillon SC, Bateman A. The hotdog fold: wrapping up a superfamily of thioesterases and dehydratases. BMC Bioinformatics. 2004;5:109.

50. Park H, Ishihara D, Cox D. Regulation of tyrosine phosphorylation in macrophage phagocytosis and chemotaxis. Arch Biochem Biophys. 2011; 510:101-11.

51. Awasthi YC, Ramana KV, Chaudhary P, Srivastava SK, Awasthi S. Regulatory roles of glutathione-S-transferases and 4-hydroxynonenal in stress-mediated signaling and toxicity. Free Radic Biol Med. 2017;111:235-43.

52. Kombrink A, Thomma BPHJ. LysM effectors: secreted proteins supporting fungal life. Plos Pathog. 2013;9:e1003769.

53. Martinez DA, Oliver BG, Gräser Y, Goldberg JM, Li W, Martinez-Rossi NM, Monod M, Shelest E, Barton RC, Birch E, Brakhage AA, Chen Z, Gurr SJ, Heiman D, Heitman J, Kosti I, Rossi A, Saif S, Samalova M, Saunders CW, Shea T, Summerbell RC, Xu J, Young S, Zeng Q, Birren BW, Cuomo CA, White TC. Comparative genome analysis of Trichophyton rubrum and related dermatophytes reveals candidate genes involved in infection. MBio. 2012;3: e00259-12.

54. Lopes L, Bitencourt TA, Lang EAS, Sanches PR, Peres NTA, Rossi A, MartinezRossi NM. Genes coding for LysM domains in the dermatophyte Trichophyton rubrum: A transcription analysis. Med Mycol. 2019. https://doi. org/10.1093/mmy/myz068.

55. Lorenz MC, Fink GR. The glyoxylate cycle is required for fungal virulence. Nature. 2001:412:83-6.

56. Komoto TT, Bitencourt TA, Silva G, Beleboni RO, Marins M, Fachin AL. Gene expression response of Trichophyton rubrum during coculture on keratinocytes exposed to antifungal agents. Evid Based Complement Alternat Med. 2015;2015(180535). https://doi.org/10.1155/2015/180535.

57. Youngchim S, Pornsuwan S, Nosanchuk JD, Dankai W, Vanittanakom N. Melanogenesis in dermatophyte species in vitro and during infection. Microbiol (Reading). 2011;157:2348-56.

58. Kane TL, Carothers KE, Lee SW. Virulence factor targeting of the bacterial pathogen Staphylococcus aureus for vaccine and therapeutics. Curr Drug Targets. 2018:19:111-27.

59. O'Meara TR, Robbins N, Cowen LE. The Hsp90 chaperone network modulates Candida virulence traits. Trends Microbiol. 2017;25:809-19.

60. Lin FY, Hsiao FP, Huang CY, Shih CM, Tsao NW, Tsai CS, Yang SF, Chang NC, Hung SL, Lin YW. Porphyromonas gingivalis GroEL induces osteoclastogenesis of periodontal ligament cells and enhances alveolar bone resorption in rats. Plos One. 2014;9:e102450.

61. Atkinson HJ, Babbitt PC, Sajid M. The global cysteine peptidase landscape in parasites. Trends Parasitol. 2009;25:573-81.

62. Drinkwater N, Lee J, Yang W, Malcolm TR, McGowan S. M1 aminopeptidases as drug targets: broad applications or therapeutic niche? FEBS J. 2017;284: 1473-88.

63. Liu, H., Hu, M., Wang, Q., Cheng, L. \& Zhang, Z. Role of papain-like cysteine proteases in plant development. Front Plant Sci. doi: https://doi.org/10.33 89/fpls.2018.01717 (2018a)

64. Liu YZ, Wang H, Zhu JH, Han DM, Kudinha T, Kong FR, Zhang QQ. Isobaric tag for relative and absolute quantitation-based comparative proteomic analysis of human pathogenic Prototheca zopfii genotype 2 and environmental genotype 1 strains. J Microbiol Immunol Infect. 2018b;51: 302-11.

65. Tefsen B, Grijpstra JF, Ordoñez SR, Lammers M, Die IV, Cock HD. Deletion of the CAP10 gene of Cryptococcus neoformans results in a pleiotropic phenotype with changes in expression of virulence factors. Res Microbiol. 2014:6:399-410.

66. Kariko K, Buckstein M, Ni H, Weissman D. Suppression of RNA recognition by Toll-like receptors: the impact of nucleoside modification and the evolutionary origin of RNA. Immunity. 2005;23:165-75. 
67. Monod M, Capoccia S, Léchenne B, Zaugg C, Holdom M, Jousson O Secreted proteases from pathogenic fungi. Int J Med Microbiol. 2002;292: 405-19.

68. Irrgang A, Murugaiyan J, Weise C, Azab W, Roesler U. Well-known surface and extracellular antigens of pathogenic microorganisms among the immunodominant proteins of the infectious microalgae Prototheca zopfii. Front Cell Infect Microbiol. 2015a;5:67

69. Irrgang A, Weise C, Murugaiyan J, Roesler U. Identification of immunodominant proteins of the microalgae Prototheca by proteomic analysis. New Microbes New Infect. 2015b;3:37-40.

70. Murugaiyan J, Eravci M, Weise C, Roesler U. Label-free quantitative proteomic analysis of harmless and pathogenic strains of infectious microalgae, Prototheca spp. Int J Mol Sci. 2016;18:59.

71. Tubaki T, Soneda M. Cultural and taxonomical studies on Prototheca. J Nagao Inst. 1959;6:25-34

72. Jagielski T, Gawor J, Bakuła Z, Zuchniewicz K, Gromadka R. An optimized method for high quality DNA extraction from microalga Prototheca wickerhamii for genome sequencing. Plant Methods. 2017;13:77.

73. Pearson WR, Wood T, Zhang Z, Miller W. Comparison of DNA sequences with protein sequences. Genomics. 1997:46:24-36.

74. Martin M. Cutadapt removes adapter sequences from high-throughput sequencing reads. EmbNET J. 2011;17:10-2.

75. De Coster W, D'Hert S, Schultz DT, Cruts M, Van Broeckhoven C. NanoPack: visualizing and processing long-read sequencing data. Bioinformatics. 2018; 34:2666-9.

76. Ruan J, Li H. Fast and accurate long-read assembly with wtdbg2. Nat Methods. 2019. https://doi.org/10.1038/s41592-019-0669-3.

77. Walker BJ, Abeel T, Shea T, Priest M, Abouelliel A, Sakthikumar S, Cuomo CA, Zeng Q, Wortman J, Young SK, Earl AM. Pilon: an integrated tool for comprehensive microbial variant detection and genome assembly improvement. PloS one. 2014;9:e112963.

78. Trapnell C, Roberts A, Goff L, Pertea G, Kim D, Kelley DR, Pimentel H, Salzberg SL, Rinn JL, Pachter L. Differential gene and transcript expression analysis of RNA-segexperiments with TopHat and cufflinks. Nat Protoc. 2012; 7:562-78.

79. Simão FA, Waterhouse RM, loannidis P, Kriventseva EV, Zdobnov EM BUSCO: assessing genome assembly and annotation completeness with single-copy orthologs. Bioinforma Oxf Engl. 2015;31:3210-2.

80. Gurevich A, Saveliev S, Vyahhi N, Tesler G. QUAST: quality assessment tool for genome assemblies. Bioinformatics. 2013;29:1072-5.

81. Smit A, Hubley R, Green P. RepeatMasker Open-4.0. http://www.repeatma sker.org. Accessed 3 Jan 2021.

82. Cantarel BL, Korf I, Robb SM, Parra G, Ross E, Moore B, Holt C, Sánchez Alvarado A, Yandell M. MAKER: an easy-to-use annotation pipeline designed for emerging model organism genomes. Genome Res. 2008;18:188-96.

83. Lomsadze A, Ter-Hovhannisyan V, Chernoff YO, Borodovsky M. Gene identification in novel eukaryotic genomes by self-training algorithm. Nucleic Acids Res. 2005;33:6494-506.

84. Hoff KJ, Stanke M. WebAUGUSTUS - a web service for training AUGUSTUS and predicting genes in eukaryotes. Nucleic Acids Res. 2013;41:123-8.

85. Hoff KJ, Lange S, Lomsadze A, Borodovsky M, Stanke M. BRAKER1: Unsupervised RNA-Seq-Based Genome Annotation with GeneMark-ET and AUGUSTUS. Bioinformatics. 2015;32:767-9.

86. Lowe TM, Eddy SR. tRNAscan-SE: a program for improved detection of transfer RNA genes in genomic sequence. Nucleic Acids Res. 1997;25: 955-64.

87. Bao W, Kojima KK, Kohany O. Repbase update, a database of repetitive elements in eukaryotic genomes. Mob DNA. 2015;6:11.

88. Altschul SF, Gish W, Miller W, Myers EW, Lipman DJ. Basic local alignment search tool. J Mol Biol. 1990;215:403-10.

89. Slater GSC, Birney E. Automated generation of heuristics for biological sequence comparison. BMC Bioinformatics. 2005;6:31.

90. Conesa A, Götz S, Garcia-Gomez JM, Terol J, Talon M, Robles M. Blast2GO: a universal tool for annotation, visualization and analysis in functional genomics research. Bioinformatics. 2005;21:3674-6.

91. Mitchell AL, Attwood TK, Babbitt PC, Blum M, Bork P, Bridge A, Brown SD, Chang HY, El-Gebali S, Fraser MI, Gough J, Haft DR, Huang H, Letunic I, Lopez R, Luciani A, Madeira F, Marchler-Bauer A, Mi H, Natale DA, Necci M, Nuka G, Orengo C, Pandurangan AP, Paysan-Lafosse T, Pesseat S, Potter SC, Qureshi MA, Rawlings ND, Redaschi N, Richardson L, Rivoire C, Salazar GA Sangrador-Vegas A, Sigrist CJA, Sillitoe I, Sutton GG, Thanki N, Thomas PD,
Tosatto SCE, Yong SY, Finn RD. InterPro in 2019: improving coverage, classification and access to protein sequence annotations. Nucleic Acids Res. 2019. https://doi.org/10.1093/nar/gky1100.

92. Karpowicz SJ, Prochnik SE, Grossman AR, Merchant SS. The GreenCut2 resource, a phylogenomically derived inventory of proteins specific to the plant lineage. J Biol Chem. 2011;286:21427-39.

93. Urban M, Cuzick A, Rutherford K, Irvine A, Pedro H, Pant R, Sadanadan V, Khamari L, Billal S, Mohanty S, Hammond-Kosack KE. PHI-base: a new interface and further additions for the multi-species pathogen-host interactions database. Nucleic Acids Res. 2017:45:604-10.

94. Rawlings ND, Barrett AJ, Thomas PD, Huang X, Bateman A, Finn RD. The MEROPS database of proteolytic enzymes, their substrates and inhibitors in 2017 and a comparison with peptidases in the PANTHER database. Nucleic Acids Res. 2018;46:624-32.

95. The UniProt Consortium. UniProt: a worldwide hub of protein knowledge. Nucleic Acids Res. 2019;47:506-15.

96. Warren IA, Ciborowski KL, Casadei E, Hazlerigg DG, Martin S, Jordan WC, Sumner S. Extensive local gene duplication and functional divergence among paralogs in Atlantic salmon. Genome Biol Evol. 2014;6:1790-805.

97. Katoh K, Standley DM. A simple method to control over-alignment in the MAFFT multiple sequence alignment program. Bioinformatics. 2016;32: 1933-42.

98. Capella-Gutiérrez S, Silla-Martínez JM, Gabaldón T. trimAl: a tool for automated alignment trimming in large-scale phylogenetic analyses. Bioinformatics. 2009;25:1972-3.

99. Stamatakis A. RAxML version 8: a tool for phylogenetic analysis and postanalysis of large phylogenies. Bioinformatics. 2014;30:1312-3.

100. Subramanian B, Gao S, Lercher MJ, Hu S, Chen W-H. Evolview v3: a webserver for visualization, annotation, and management of phylogenetic trees. Nucleic Acids Res. 2019;47:W270-5.

\section{Publisher's Note}

Springer Nature remains neutral with regard to jurisdictional claims in published maps and institutional affiliations.

\section{Ready to submit your research? Choose BMC and benefit from:}

- fast, convenient online submission

- thorough peer review by experienced researchers in your field

- rapid publication on acceptance

- support for research data, including large and complex data types

- gold Open Access which fosters wider collaboration and increased citations

- maximum visibility for your research: over $100 \mathrm{M}$ website views per year

At BMC, research is always in progress.

Learn more biomedcentral.com/submissions 